\title{
Artesunate influences Th17/Treg lymphocyte balance by modulating Treg apoptosis and Th17 proliferation in a murine model of rheumatoid arthritis
}

\author{
JIA LIU, XUEZHI HONG, DONG LIN, XIAOHONG LUO, MENGYAZHU and HANYOU MO \\ Department of Clinical Immunology and Rheumatology, The Affiliated Hospital of Guilin Medical College, \\ Guilin Medical University, Guilin, Guangxi 541001, P.R. China
}

Received April 3, 2015; Accepted May 5, 2016

DOI: $10.3892 /$ etm.2017.4232

\begin{abstract}
CD}^{+}$regulatory $\mathrm{T}$ (Treg) cells and T-helper 17 (Th17) cells have been shown to have important roles in rheumatoid arthritis (RA). In our previous study, it was demonstrated that artesunate was able to alter the Treg/Th17 ratio in patients with $\mathrm{RA}$; however, the underlying mechanisms remain unclear. The present study established a male Sprague Dawley (SD) rat model of type II collagen-induced arthritis (CIA). SD rats were divided into normal control, CIA model and artesunate-treated $(5,10$ or $20 \mathrm{mg} / \mathrm{kg} / \mathrm{day})$ groups. Treg and Th17 cells were detected in the synovium by immunohistochemical analysis of forkhead/winged helix transcription factor (Foxp3) and interleukin (IL)-17 expression. Subsequently, lymphocytes were extracted from the rat spleens, and the proportions of Treg/Th17 cells were detected by flow cytometry. The results demonstrated that the expression levels of Foxp3 were significantly decreased, and those of IL-17 were significantly increased, in the CIA model group, as compared with the normal control group. The results demonstrated that artesunate decreased the frequency of Th17 cells and increased the frequency of Treg cells in CIA rats in a dose-dependent manner. In conclusion, the present study suggested that artesunate may regulate the Th17/Treg balance by inducing Th17-mediated apoptosis. Therefore, artesunate may be considered a novel therapeutic agent for the treatment of patients with RA.
\end{abstract}

Correspondence to: Professor Hanyou Mo, Department of Clinical Immunology and Rheumatology, The Affiliated Hospital of Guilin Medical College, Guilin Medical University, 15 Xiufeng Lequn Road, Guilin, Guangxi 541001, P.R. China E-mail: mohanyou@hotmail.com

Key words: rheumatoid arthritis, artesunate, $\mathrm{T}$ helper 17, regulatory T-cells

\section{Introduction}

Rheumatoid arthritis (RA) is a chronic disease involving various immune cells, particularly $\mathrm{T}$ lymphocytes, such as $\mathrm{CD}^{+}$T-helper (Th) cells $(1,2)$. RA is characterized by chronic inflammation of the joints, synovial hyperplasia and abnormal systemic immune responses. The joint damage that underlies the pathogenesis of RA resembles the process of immune-mediated tumor destruction (3). The formation of blood vessels and degradation of the extracellular matrix are crucial steps in the process of erosion, and $\mathrm{T}$ lymphocytes have an important role in these coronary events (4).

$\mathrm{CD} 4^{+} \mathrm{T}$ cells may differentiate into various lineages that are characterized by their profiles of secreted cytokines. $\mathrm{CD}^{+}$ regulatory $\mathrm{T}$ (Treg) cells and Th17 cells have been described as two original subsets that are distinct from Th1 and Th2 cells. Treg cells, which are characterized by the expression of forkhead/winged helix transcription factor (Foxp3), are essential for regulating self-tolerance and have exhibited anti-inflammatory functions via contact-dependent suppression or by the release of anti-inflammatory cytokines (5). A lack of Treg cells has previously been associated with autoimmune diseases (6). Th17 cells express retinoic acid-related orphan receptor $\gamma t$ and have critical roles in the development of autoimmune diseases and human inflammatory conditions by producing a novel cytokine, interleukin (IL)-17 (7). It has been demonstrated that an imbalance in Th17/Treg cells had an important role in joint inflammation and destruction in an animal model (8). A previous study demonstrated that the imbalance between Th17 and Treg cells is an important mechanism which may lead to RA (2).

Artesunate is a low toxicity and highly efficient immune inhibitor (9). It has previously been demonstrated that artesunate is able to suppress lipopolysaccharide-induced secretion of tumor necrosis factor (TNF)- $\alpha$ by synovial cells by regulating nuclear factor- $\kappa \mathrm{B}$ signaling pathways $(10,11)$, thereby inhibiting the synovial inflammation associated with RA. In addition, artesunate inhibited the secretion of IL-17, TNF- $\alpha$ and other inflammatory factors by synovial cells in previous studies $(12,13)$; thus reducing the formation of pannus and erosion of cartilage and bone. However, the effect of artesunate on the balance of Th17/Treg cells in patients with RA remains unknown. 
The present study established a rat model of type II collagen-induced arthritis (CIA) in order to investigate the effect of artesunate on the Th17/Treg cell imbalance in vivo and to elucidate the underlying mechanisms.

\section{Materials and methods}

Experimental animals. A total of 70 male Sprague Dawley rats (weight, $100 \mathrm{~g}$; age, 4 weeks) were obtained from the Guilin Medical College Experimental Animal Center (Guilin, China). The rats were maintained at $22-26^{\circ} \mathrm{C}$ and $55 \pm 10 \%$ humidity, under a 12-h light/dark cycle with ad libitum access to food and water. The present study was approved by the Ethics Committee of Guilin Medical University (Guilin, China).

Reagents. Collagen type II (5 ml/bottle) was purchased from Chondrex, Inc., (Redmond, WA, USA); Complete Freund's adjuvant (CFA; $10 \mathrm{ml} /$ bottle) was obtained from Sigma-Aldrich (St. Louis, MO, USA); artesunate was purchased from Guilin Pharmaceutical Co., Ltd., (Guilin, China); Leukocyte Activation Cocktail with BD GolgiPlug ${ }^{\mathrm{TM}}$ and Lysing Buffer were purchased from BD Pharmingen (San Diego, CA, USA); phycoerythrin (PE)-conjugated anti-rat IL-17A, PE-conjugated anti-rat Foxp3, allophycocyanin (APC)-conjugated anti-rat CD4, PE-conjugated rat IgG2a Isotype Control and the Foxp3/Transcription Factor Staining Buffer Set were obtained from eBioscience, Inc., (San Diego, CA, USA); anti-IL-17 and anti-Foxp3 antibodies were purchased from Abcam (Cambridge, UK).

Establishment of a CIA murine model. Collagen type II (with acetic acid, $2 \mathrm{mg} / \mathrm{ml}$ ) was slowly added to an equal volume of CFA to a final concentration of $1 \mathrm{mg} / \mathrm{ml}$ and maintained on ice until further use. Subsequently, rats were anesthetized with pentobarbital sodium (0.1 ml/100 g; Sigma-Aldrich) and divided into the normal control $(n=9)$ and the CIA model $(n=8)$ groups. The CIA model group was administered a mixed emulsion $(0.2 \mathrm{ml})$ of collagen and adjuvant $(1 \mathrm{mg} / \mathrm{ml}$ acetic acid) by intradermal injection in the rat tail, and the normal control group was administered an equal volume of saline. Primary immunization was performed on day 0 with $200 \mathrm{mg}(0.2 \mathrm{ml})$, followed by a second immunization on day 7 with $100 \mathrm{mg}$ $(0.1 \mathrm{ml})$. Rats that scored $>6$ points in the arthritis index (AI) scoring system (14) were used for subsequent analyses.

Treatment with artesunate. CIA rats were divided into four sub-groups, as follows: i) CIA model plus $2 \mathrm{ml}$ saline; ii) CIA model plus $5 \mathrm{mg} / \mathrm{kg} / \mathrm{day}$ artesunate; iii) CIA model plus $10 \mathrm{mg} / \mathrm{kg} /$ day artesunate; and iv) CIA model plus $20 \mathrm{mg} / \mathrm{kg} /$ day artesunate. Daily artesunate gavage was initiated on day 14 following primary immunization. All rats were sacrificed in week 20 by cervical dislocation following intraperitoneal injection with $10 \%$ chloral hydrate (OriGene Technologies, Inc., Beijing, China). The normal control group was administered an equal volume of physiological saline.

Evaluation of clinical features. Clinical features of the rats were analyzed once a week following primary immunization. This included an assessment of the general health of the rats, including their weight, fur color, feeding behaviour and AI. In addition, the drainage method was used to assess the degree of swelling of the hind legs, as described previously (15).

Degree of joint swelling. A vernier caliper was used to measure the radius of the left leg ankle (from the medial malleolus to the external ankle) and the diameter from the foot heel to the middle point of joint clearance, in order to assess the general incidence degree of joint swelling and the effect of treatment by analyzing the anteroposterior and transverse diameters.

AI. The AI of each rat was calculated prior to primary immunization, following primary immunization, once every 3 days in the acute phase during the initial 6 weeks and once every week in the chronic phase, according to a previous study (16). Briefly, each claw was assigned 4 points, thus the maximum possible score for each rat was 16 points. However, as pathological changes predominantly occurred in the hind legs of rats in the present study, a score of 6-8 points was deemed to indicate severe arthritis.

Molybdenum target X-ray. Joint damage in the left posterior ankle was observed by molybdenum target X-ray mammography at 10 and 21 weeks following primary immunization of the normal control, CIA model and CIA model plus artesunate $(20 \mathrm{mg} / \mathrm{kg} /$ day) groups. The stage of arthritis was subsequently determined according to the American Rheumatism Association criteria for the classification of rheumatoid arthritis (17), as follows: Normal (0), osteoporosis period $(+)$, bone destruction period $(++)$, bone serious destruction period $(+++)$ and ankylosis period $(++++)$.

Histopathological analysis. Rats were sacrificed at week 20 and the left anklebone was harvested, fixed with $10 \%$ neutral formalin for $24 \mathrm{~h}$, decalcified using 10\% EDTA, cut vertically, embedded in paraffin and cut into $2-\mu \mathrm{m}$ slices. Subsequently, the slices were stained with hematoxylin and eosin in order to observe inflammation in the joint under a light microscope, according to a previous study (18). The slices were observed for infiltration of inflammatory cells, including neutrophils, lymphocytes and plasma cells, synovial cell hyperplasia, proliferation of fibrous tissue and erosion of bone and cartilage.

Immunohistochemical analysis. Sections were dewaxed and incubated with citric acid in a pressure cooker for antigen retrieval. After this, the sections were incubated with $0.3 \% \mathrm{H}_{2} \mathrm{O}_{2}$ for $3 \mathrm{~min}$, washed three times for $3 \mathrm{~min}$ each with phosphate-buffered saline (PBS) and incubated with PE-conjugated anti-IL-17A and anti-Foxp3 antibodies for $1 \mathrm{~h}$ at $37^{\circ} \mathrm{C}$. Subsequently, the sections were washed three times for 3 min each with PBS, followed by incubation with the secondary antibody for $1 \mathrm{~h}$ at room temperature. Antibody complexes were visualized with 3,3'-diaminobenzidine, after which the sections were stained with hematoxylin, dehydrated and mounted with gum, prior to visualization under a fluorescent microscope.

Extraction of spleen lymphocytes. Following sacrifice, the rats were soaked in $75 \%$ ethanol for $10 \mathrm{~min}$ and the spleen 
was harvested under sterile conditions. Subsequently, the spleen was cut into small pieces using ophthalmic scissors, homogenized and filtered using a 200-mesh steel sieve with the core of a $5 \mathrm{ml}$ syringe to remove large pieces of tissue. The homogenate was centrifuged at $400 \mathrm{x}$ g for $5 \mathrm{~min}$ at $4^{\circ} \mathrm{C}$, the supernatant was discarded and $5 \mathrm{ml}$ Lysing Buffer was added to the pellet. Spleen cells were subsequently washed 1-2 times with PBS, after which $10^{6}$ cells/ml underwent flow cytometry in four tubes.

Flow cytometry. Leukocyte Activation Cocktail, with BD GolgiPlug $^{\mathrm{TM}}(0.5 \mu \mathrm{l})$ was added to each tube and incubated at $37^{\circ} \mathrm{C}$ in $5 \% \mathrm{CO}_{2}$ for $6 \mathrm{~h}$. Subsequently, $1 \mathrm{ml}$ fluorescence-activated cell sorting (FACS) buffer (50 ml 10X PBS, $20 \mathrm{~g}$ bovine serum albumin, $0.02 \% \mathrm{NaN}_{3}$, distilled water) was added to each tube, followed by centrifugation at $400 \mathrm{x} \mathrm{g}$ for $5 \mathrm{~min}$ at $4^{\circ} \mathrm{C}$. The supernatant was discarded and the pellet was resuspended in $100 \mu \mathrm{l}$ FACS buffer, followed by the addition of $5 \mu \mathrm{l}$ APC-conjugated CD4 and centrifugation at $350 \mathrm{xg}$ for $5 \mathrm{~min}$ at $4^{\circ} \mathrm{C}$. In order to rupture the cell membranes, $1 \mathrm{ml}$ Foxp3/permeabilization buffer (BD Pharmingen) was added to each tube and the tubes were incubated at $4^{\circ} \mathrm{C}$ for $40 \mathrm{~min}$ in the dark. Subsequently, $2 \mathrm{ml}$ permeabilization buffer $(1 \mathrm{X})$ was added to each tube and the tubes were centrifuged at $350 \mathrm{xg}$ for $5 \mathrm{~min}$ at $4^{\circ} \mathrm{C}$. The resulting pellet was resuspended in $100 \mu 1$ permeabilization buffer (1X), followed by the addition of 5 or $10 \mu \mathrm{l}$ PE-conjugated rat $\operatorname{IgG} 2 \mathrm{a}$ isotype control, $5 \mu 1$ PE-conjugated anti-Foxp3 or $10 \mu \mathrm{l}$ PE-conjugated anti-IL-17 at $4{ }^{\circ} \mathrm{C}$ for $30 \mathrm{~min}$ in the dark. The tubes were analyzed on a flow cytometer using BD FACSDiva ${ }^{\mathrm{TM}}$ Software 6.0 (BD Pharmingen).

Statistical analysis. SPSS 17.0 software (SPSS, Inc., Chicago, IL, USA) was used to conduct statistical analyses. Data were presented as the mean \pm standard deviation. One-way analysis of variance was performed to analyze differences among groups. Dunnett's T3 test was used to compare non-parametric data. $\mathrm{P}<0.05$ was considered to indicate a statistically significant difference.

\section{Results}

Clinical features of CIA rats. Of the 61 rats in the CIA model group, 56 exhibited arthritic symptoms in 9-21 days following primary immunization (success rate, $23.3 \%$ ). Arthritis appeared at 9 days following the primary immunization as redness and swelling in the small toe, foot or ankle. As demonstrated in Fig. 1, AI peaked at $~ 42$ days following immunization in the CIA model group, which was followed by a chronic arthritis phase. At 70 days post-primary immunization, the mean AI was 9 points for the $5 \mathrm{mg} / \mathrm{kg} / \mathrm{day}$ artesunate group, 7 points for the $10 \mathrm{mg} / \mathrm{kg} / \mathrm{day}$ artesunate group, 5 points for the $20 \mathrm{mg} / \mathrm{kg} /$ day artesunate group, and 10.5 points for the CIA group. At 142 days post-primary immunization, the mean AI was 7 points for the $5 \mathrm{mg} / \mathrm{kg} /$ day artesunate group, 5 points for the $10 \mathrm{mg} / \mathrm{kg} /$ day artesunate group, 3 points for the $20 \mathrm{mg} / \mathrm{kg} /$ day artesunate group and 11.1 points for the CIA group. These results suggest that $20 \mathrm{mg} / \mathrm{kg} /$ day artesunate is able to improve joint symptoms in a rat model of $\mathrm{RA}$.
Table I. Expression of Foxp3/ IL-17 in CD4 ${ }^{+} \mathrm{T}$ lymphocytes.

\begin{tabular}{lll}
\hline Group & Foxp3 $(\%)$ & IL-17 $(\%)$ \\
\hline Normal & $1.171 \pm 0.191^{\mathrm{a}}$ & $0.514 \pm 0.352$ \\
CIA model & $0.529 \pm 0.138^{\mathrm{a}, \mathrm{b}}$ & $1.471 \pm 0.180^{\mathrm{a}, \mathrm{b}}$ \\
Artesunate $(\mathrm{mg} / \mathrm{kg} /$ day $)$ & & \\
5 & $0.729 \pm 0.095^{\mathrm{a}}$ & $1.257 \pm 0.134^{\mathrm{a}, \mathrm{b}}$ \\
10 & $1.342 \pm 0.217^{\mathrm{a}, \mathrm{b}}$ & $0.829 \pm 0.040^{\mathrm{a}, \mathrm{b}}$ \\
20 & $1.671 \pm 0.123^{\mathrm{b}}$ & $0.600 \pm 0.038$ \\
\hline
\end{tabular}

${ }^{\mathrm{a}} \mathrm{P}<0.01$ vs. the $20 \mathrm{mg} / \mathrm{kg} /$ day artesunate group; ${ }^{\mathrm{b}} \mathrm{P}<0.01 \mathrm{vs}$. the normal group. Foxp3, forkhead/winged helix transcription factor; IL, interleukin; CIA, collagen-induced arthritis.

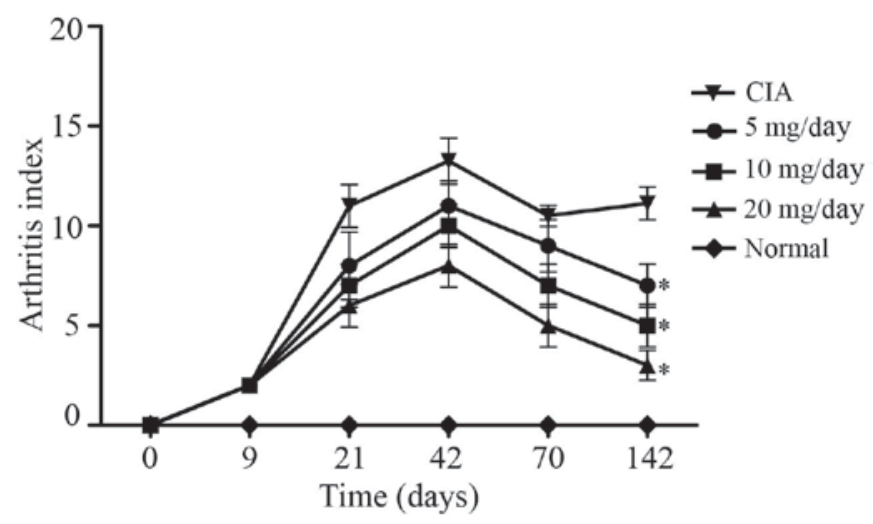

Figure 1. Arthritis indices of the rat models of type II collagen-induced arthritis. ${ }^{*} \mathrm{P}<0.05$ vs. CIA.

Histopathological analysis of rat ankle joints. As compared with the normal control rats, the levels of synovial fluid in the CIA rats were increased, the joint cavity was disorganized, and infiltration of inflammatory cells, in particular lymphocytes and monocytes, and synovial pannus invasion of joint cartilage and bone, were observed at 10 weeks following primary immunization (Figs. 2A and B). At 21 weeks following the primary immunization, the levels of synovial fluid were increased, the joint cavity was disordered, and infiltration of inflammatory cells and cartilage and bone damage were observed in the CIA rats (Fig. 2C). These results suggested that the rat model of CIA had been established successfully.

Molybdenum target X-rays of rat limb joints. The structure of the joint cavity was integrated in normal rats. Conversely, CIA rats exhibited signs of osteoporosis, bone and articular cartilage destruction and narrowed joint spaces at weeks 10 and 21 following primary immunization. Rats in the $20 \mathrm{mg} / \mathrm{kg} /$ day artesunate group exhibited signs of osteoporosis; however, bone destruction was mild (Fig. 2). These results suggest that artesunate is able to attenuate the bone destruction associated with RA.

Expression of Foxp3 and $\mathrm{Il}-17$ in the synovium. Immunohistochemical analysis demonstrated that Foxp3 was dispersed in the synovial lining cell layer, surrounding blood vessels 
A

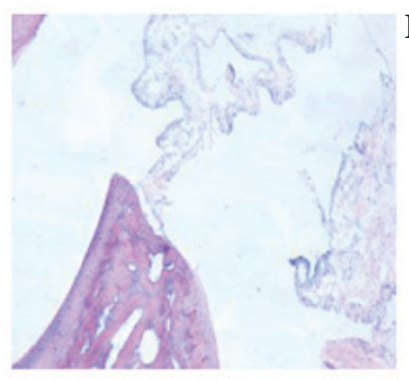

D

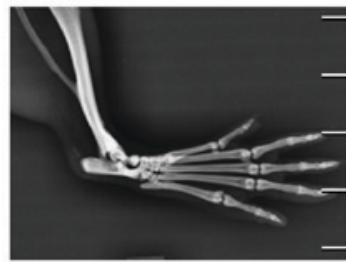

G

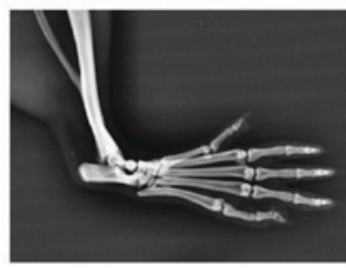

H
B
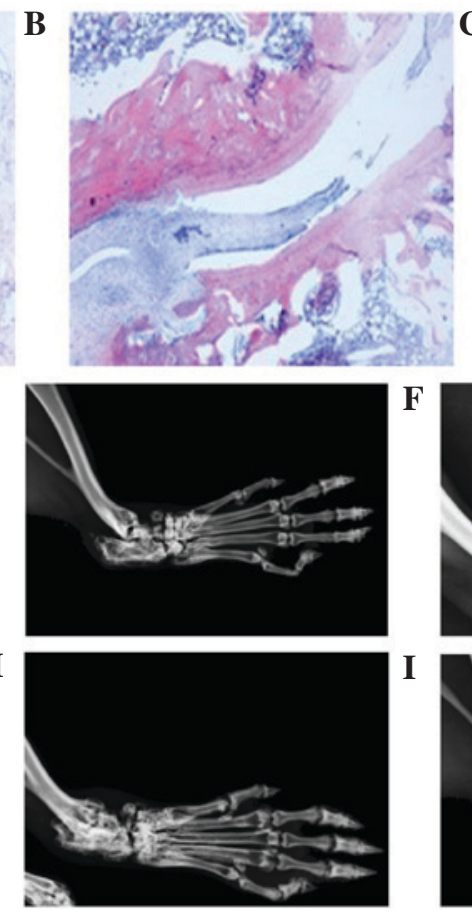

C
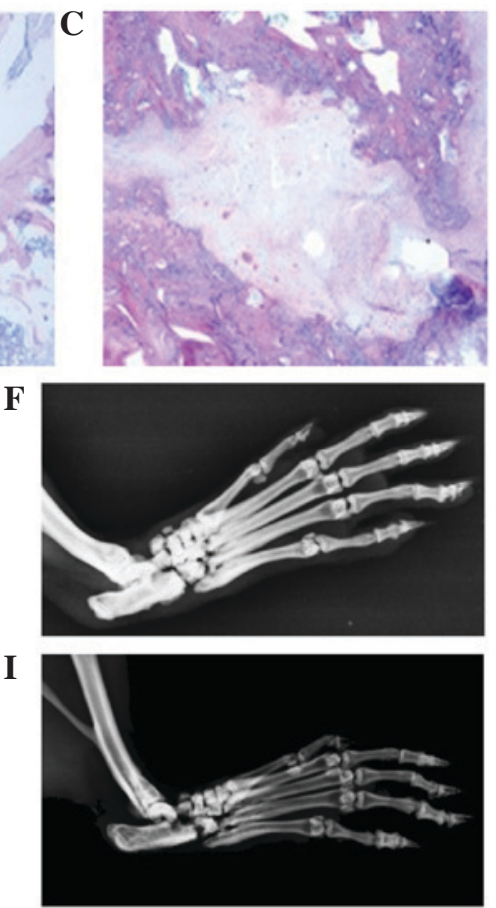

Figure 2. Pathological sections of ankle joints and molybdenum target X-rays of rat limb joints. Pathological sections of ankle joints from (A) a normal rat, (B) a CIA rat at 10 weeks post-primary immunization and (C) a CIA rat at 21 weeks post-primary immunization (magnification, $\mathrm{x} 400$ ). Molybdenum target X-rays of the rat limb joints from (D) a normal control group rat at 10 weeks post-primary immunization, (E) a CIA rat at 10 weeks post-primary immunization, (F) an artesunate-treated ( $20 \mathrm{mg} / \mathrm{kg} / \mathrm{day})$ rat at 10 weeks post-primary immunization, (G) a normal control group rat at 21 weeks post-primary immunization, (H) a CIA rat at 21 weeks post-primary immunization and (I) an artesunate-treated (20 mg/kg/day) rat at 21 weeks post-primary immunization. CIA, collagen-induced arthritis.
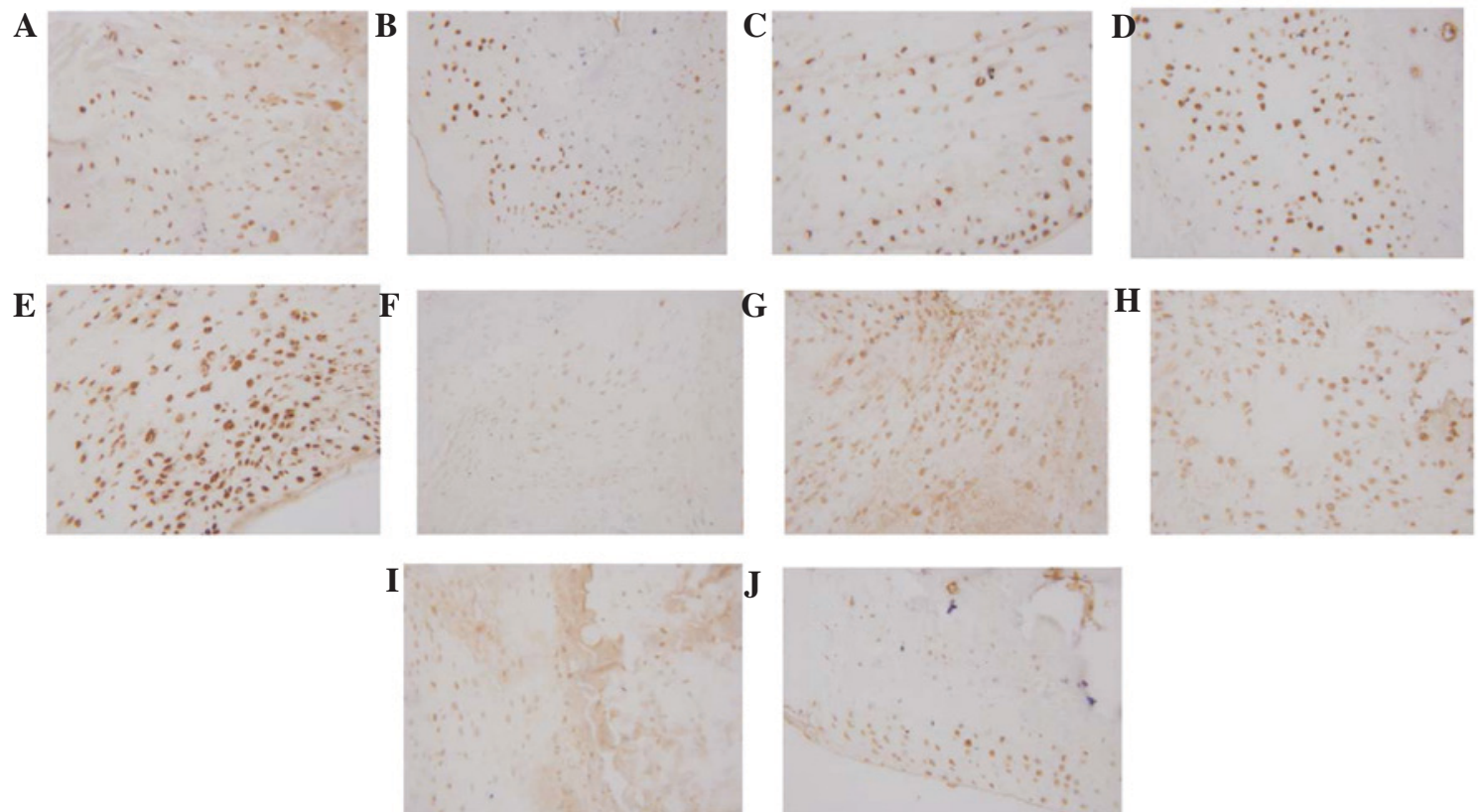

Figure 3. Expression of Foxp3/IL-17 in the synovium, as determined by immunohistochemial staining (magnification, x400). Foxp3 expression in the (A) normal control, (B) collagen-induced arthritis model, (C) $5 \mathrm{mg} / \mathrm{kg} /$ day artesunate, (D) $10 \mathrm{mg} / \mathrm{kg} / \mathrm{day}$ artesunate and (E) $20 \mathrm{mg} / \mathrm{kg} / \mathrm{day}$ artesunate groups IL-17 expression in the (F) normal control, (G) CIA model, (H) $5 \mathrm{mg} / \mathrm{kg} /$ day artesunate, (I) $10 \mathrm{mg} / \mathrm{kg} /$ day artesunate and (J) $20 \mathrm{mg} / \mathrm{kg} / \mathrm{day}$ artesunate groups. Foxp3, forkhead/winged helix transcription factor; IL-17, interleukin-17.

and cartilage surface, and IL-17 was predominantly located in the synovial lining cell layer and surrounding blood vessels. Expression levels of Foxp3 were markedly increased in the $20 \mathrm{mg} / \mathrm{kg} / \mathrm{day}$ artesunate group, as compared with the other drug intervention groups and CIA group; however, no marked difference was observed between the $20 \mathrm{mg} / \mathrm{kg} /$ day artesunate group and the normal control group. The expression levels of IL-17 were markedly reduced in the $20 \mathrm{mg} / \mathrm{kg} /$ day artesunate 
A

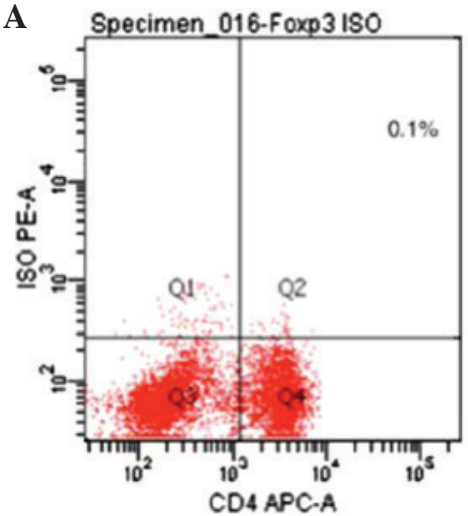

D

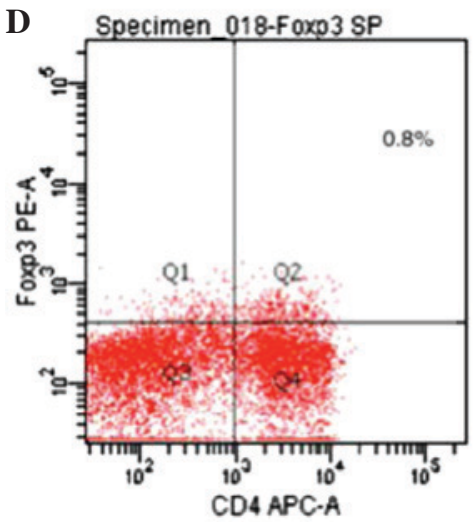

B

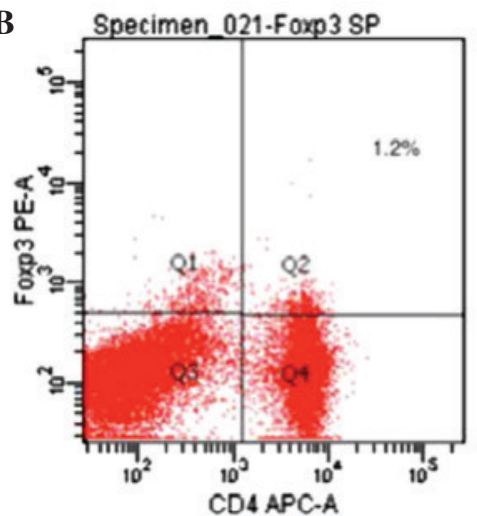

$\mathbf{E}$

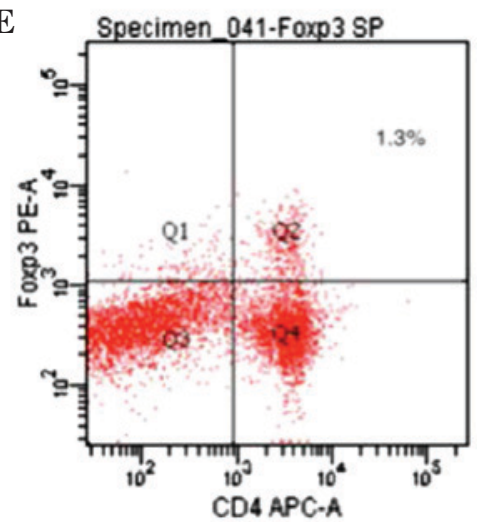

$\mathrm{C}$

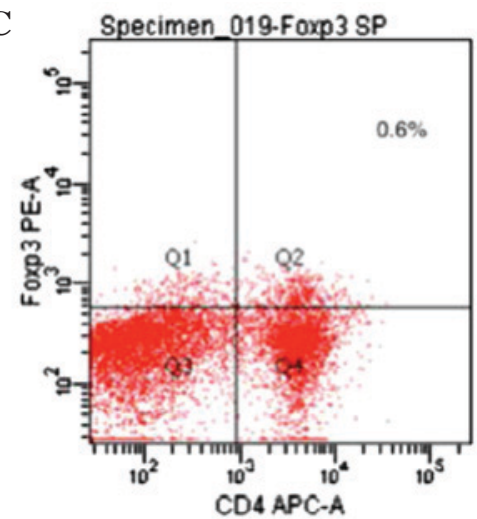

$\mathbf{F}$

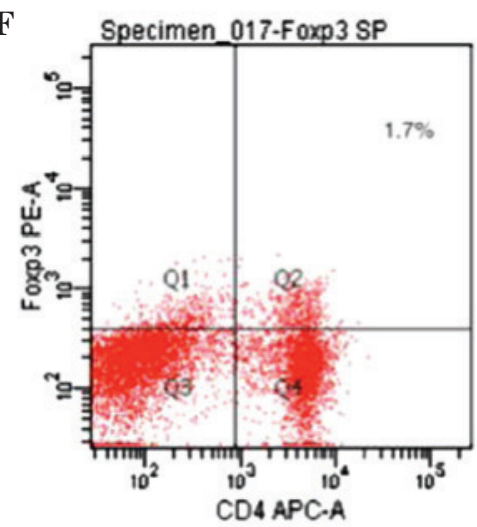

Figure 4. Expression of Foxp3 in CD4 ${ }^{+}$T lymphocytes. Spleen cells were incubated with APC-conjugated anti-CD4 and PE-conjugated anti-Foxp3 antibodies and analyzed by flow cytometry. (A) Foxp3 isotype control; (B) normal control group; (C) collagen-induced arthritis model group; (D) 5 mg/kg/day artesunate group; (E) $10 \mathrm{mg} / \mathrm{kg} /$ day artesunate group; (F) $20 \mathrm{mg} / \mathrm{kg} /$ day artesunate group. Foxp3, forkhead/winged helix transcription factor; APC, allophycocyanin; PE, phycoerythrin.

A

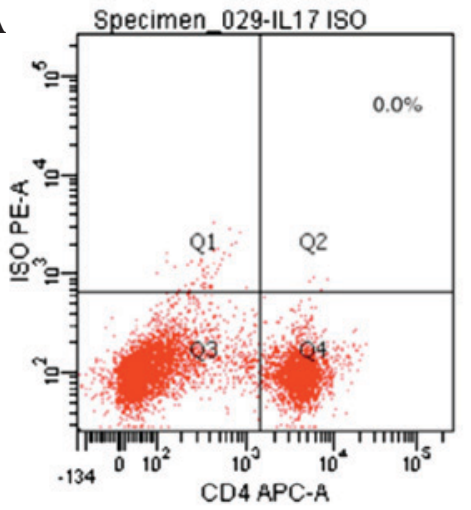

D

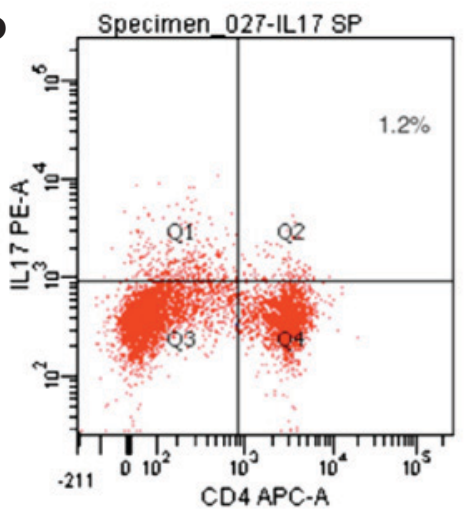

B

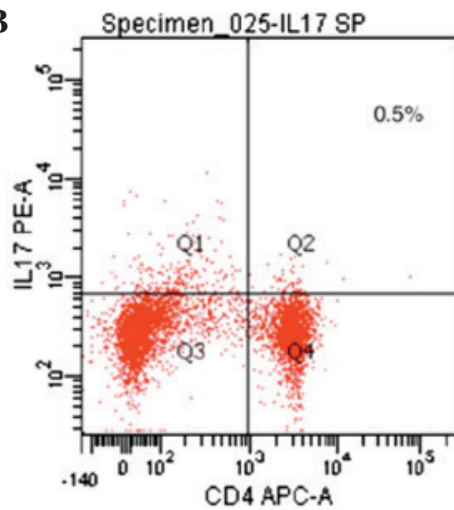

E Specimen_018-IL17 SP_new

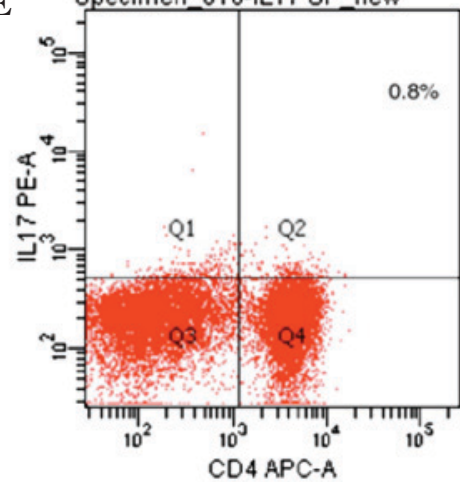

C

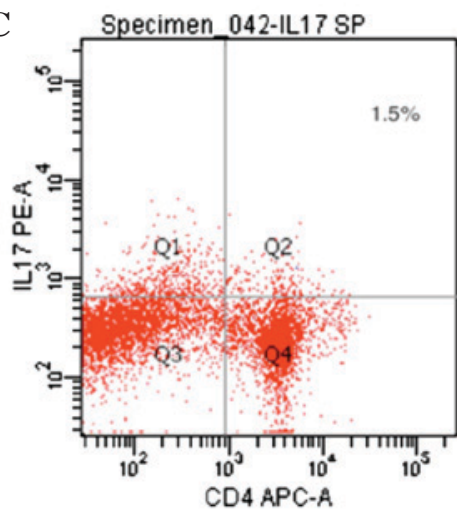

$\mathbf{F}$

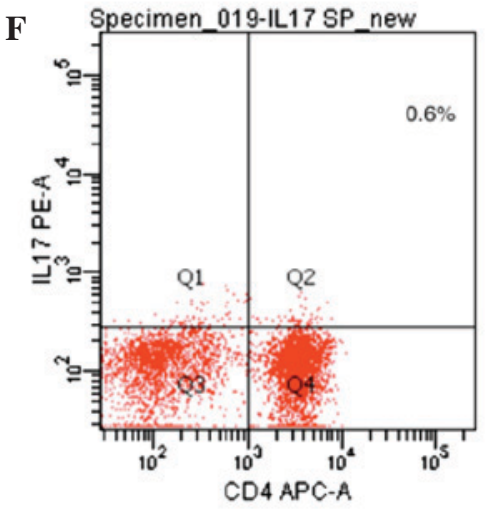

Figure 5. Expression of IL-17 in CD4 ${ }^{+}$T lymphocytes. Spleen cells were incubated with APC-conjugated anti-CD4 and PE-conjugated anti-IL-17 antibodies and analyzed by flow cytometry. (A) IL-17 isotype control; (B) normal control group; (C) collagen-induced arthritis model group; (D) 5 mg/kg/day artesunate group; (E) $10 \mathrm{mg} / \mathrm{kg} /$ day artesunate group; (F) $20 \mathrm{mg} / \mathrm{kg} /$ day artesunate group. IL-17, interleukin-17; APC, allophycocyanin; PE, phycoerythrin. 
group, as compared with the CIA group and the other drug intervention groups (Fig. 3).

Expression of Foxp3 in spleen T lymphocytes, as detected by flow cytometry. Foxp3 expression is an indicator of Treg cells. As compared with the normal control group, the expression levels of Foxp3 were significantly decreased in the CIA model group, as compared with the normal control group $(\mathrm{P}<0.05)$. The expression levels of Foxp3 were significantly increased in the $20 \mathrm{mg} / \mathrm{kg} /$ day artesunate group, as compared with the $10 \mathrm{mg} / \mathrm{kg} /$ day artesunate and $5 \mathrm{mg} / \mathrm{kg} /$ day artesunate groups $(\mathrm{P}<0.05$; Table I and Fig. 4).

Expression of IL-17 in spleen T lymphocytes, as detected by flow cytometry. IL-17 expression is an indicator of Th17 cells. As compared with the normal control group, the expression levels of IL-17 were significantly increased in the CIA model group $(\mathrm{P}<0.05)$. The expression levels of IL-17 were significantly decreased in the $20 \mathrm{mg} / \mathrm{kg} /$ day artesunate group, as compared with the $10 \mathrm{mg} / \mathrm{kg} /$ day artesunate and $5 \mathrm{mg} / \mathrm{kg} /$ day artesunate groups $(\mathrm{P}<0.05$; Table I and Fig. 5).

\section{Discussion}

RA is a systemic autoimmune disease characterized by peripheral arthritis. At present, the CIA model is the most commonly used animal model for studying RA (19). The underlying etiology and pathogenesis of RA has yet to be fully elucidated, although the expression and balance of Th17/Treg lymphocytes has emerged as a hot research topic in autoimmune diseases. Niu et al (2) reported that Th17 cells were significantly increased, whereas Treg cells were significantly decreased, in the peripheral blood of patients with RA, as compared with healthy controls; thus suggesting that an imbalance of Th17/Treg lymphocytes may underlie the pathogenesis of RA. This is consistent with the present study, which demonstrated that the expression levels of Foxp3 were decreased, and those of Il-17 were increased, in spleen lymphocytes derived from CIA rats.

Artemisinin and its derivatives are the most effective and safe therapeutic agents for the treatment of malignant and chloroquine-resistant malaria (20). In addition, it has been suggested that artemisinin and its derivatives may also exert anti-inflammatory and immunomodulatory effects (21). Artesunate is a semi-synthetic derivative of artemisinin. In our previous study, it was demonstrated that artesunate was able to regulate the NF- $\kappa \mathrm{B}$ signaling pathway to inhibit LPS-induced secretion of TNF- $\alpha$ by RA synovial cells, and it was able to lower the activity of IL-17 (13). One aim of the present study was to investigate whether artesunate reduces the activity of IL-17 via increasing the expression of Foxp3, thereby exerting immunomodulatory effects.

The present study demonstrated that intervention with artesunate resulted in an increase in the number of Foxp3-positive T-cells and a decrease in the number of IL-17-positive $\mathrm{T}$ cells in a dose-dependent manner. These results suggested that artesunate was able to correct the imbalance of Th17/Treg cells in CIA rats. Traditional treatment of RA involves administration of hydroxychloroquine and methotrexate (22).
The greatest effects were observed with $20 \mathrm{mg} / \mathrm{kg} /$ day artesunate. The results of the present study suggested that artesunate was able to control and alleviate the symptoms of CIA rats. A previous study suggested that the effects of artesunate may involve the inhibition of IL-17, TNF- $\alpha$, MMP3 and other inflammatory factors (23), and the present study demonstrated that these immunomodulatory effects may occur via the induction of Foxp3 expression.

In conclusion, the present study demonstrated that artesunate was able to increase the expression of Foxp3 and decrease the expression of IL-17 in CD4 ${ }^{+} \mathrm{T}$ lymphocytes, thereby reversing the imbalance of Th17/Treg cells associated with arthritis. Our investigations of artesunate have identified potential therapeutic targets of artesunate and have highlighted a potential mechanism underlying the intervention of artesunate in human synovial cells. However, further studies to elucidate the potential adverse reactions of artesunate are required prior to the widespread clinical use of artesunate for the treatment of RA.

\section{Acknowledgements}

The present study was supported by grants from the Chinese National Natural Science Foundation (grant nos. 81160376 and 81360462), the Guangxi Natural Science Foundation (grant nos.2013GXNSFAA019111 and2013GXNSFBA019181), the Guangxi Department of Education Natural Science Foundation (grant no. 201106LX363) and the Guilin Natural Science Foundation (grant no. 20120121-1-7)

\section{References}

1. Guggino G, Giardina A, Ferrante A, Giardina G, Schinocca C, Sireci G, Dieli F, Ciccia F and Triolo G: The in vitro addition of methotrexate and/or methylprednisolone determines peripheral reduction in Th17 and expansion of conventional Treg and of IL-10 producing Th17 lymphocytes in patients with early rheumatoid arthritis. Rheumatol Int 35: 171-175, 2015.

2. Niu Q, Cai B, Huang ZC, Shi YY and Wang LL: Disturbed Th17/Treg balance in patient with rheumatoid arthritis. Rheumatol Int 32: 2731-2736, 2012.

3. Firestein GS: Evolving concepts of rheumatoid arthritis. Nature 423: 356-361, 2003.

4. Kolb C, Mauch S, Peter HH, Krawinkel U and Sedlacek R: The matrix metalloproteinase RASI-1 is expressed in synovial blood vessels of a rheumatoid arthritis patient. Immunol Lett 57: 83-88, 1997.

5. Sakaguchi S, Ono M, Setoguchi R, Yagi H, Hori S, Fehervari Z, Shimizu J, Takahashi T and Nomura T: Foxp $3^{+} \mathrm{CD} 25^{+} \mathrm{CD} 4^{+}$ natural regulatory $\mathrm{T}$ cells in dominant self-tolerance and autoimmune disease. Immunol Rev 212: 8-27, 2006.

6. Dejaco C, Duftner C, Grubeck-Loebenstein B and Schirmer M: Imbalance of regulatory T cells in human autoimmune diseases. Immunology 117: 289-300, 2006.

7. Bettelli E, Oukka M and Kuchroo VK: T(H)-17 cells in the circle of immunity and autoimmunity. Nat Immunol 8: 345-350, 2007.

8. Boissier MC, Assier E, Falgarone G and Bessis N: Shifting the imbalance from Th1/Th2 to Th17/treg: The changing rheumatoid arthritis paradigm. Joint Bone Spine 75: 373-375, 2008.

9. Xu H, He Y, Yang X, Liang L, Zhan Z, Ye Y, Yang X, Lian F and Sun L: Anti-malarial agent artesunate inhibits TNF-alpha induced production of proinflammatory cytokines via inhibition of NF-kappaB and PI3 kinase/Akt signal pathway in human rheumatoid arthritis fibroblast-like synoviocytes. Rheumatology (Oxford) 46: 920-926, 2007.

10. Li Y, Wang S, Wang Y, Zhou C, Chen G, Shen W, Li C, Lin W, Lin S, Huang H, et al: Inhibitory effect of the antimalarial agent artesunate on collagen-induced arthritis in rats through nuclear factor kappaB and mitogen-activated protein kinase signaling pathway. Transl Res 161: 89-98, 2013. 
11. Li B, Yu M, Pan X, Ren C, Peng W, Li X, Jiang W, Zheng J and Zhou H: Artesunate reduces serum lipopolysaccharide in cecal ligation/puncture mice via enhanced LPS internalization by macrophages through increased mRNA expression of scavenger receptors. Int J Mol Sci 15: 1143-1161, 2014

12. Yang Z, Ding J, Yang C, Gao Y, Li X, Chen X, Peng Y, Fang J and Xiao S: Immunomodulatory and anti-inflammatory properties of artesunate in experimental colitis. Curr Med Chem 19: 4541-4551, 2012.

13. Mo HY, Wang LF and Zhang LH: Effects of artesunate on tumor necrosis factor alpha and chemotactic factors in the serum and the synoviocyte culture supernate of collagen-induced arthritis rats. Zhongguo Zhong Xi Yi Jie He Za Zhi 32: 253-256, 2012 (In Chinese)

14. Cuzzocrea S, Mazzon E, Bevilaqua C, Costantino G, Britti D Mazzullo G, De Sarro A and Caputi AP: Cloricromene, a coumarine derivative, protects against collagen-induced arthritis in Lewis rats. Br J Pharmacol 131: 1399-1407, 2000.

15. Brahn E, Peacock DJ and Banquerigo ML: Suppression of collagen-induced arthritis by combination cyclosporin A and methotrexate therapy. Arthritis Rheum 34: 1282-1288, 1991.

16. Mukherjee P, Yang SY, Wu B, Song Z, Myers LK, Robbins PD and Wooley PH: Tumour necrosis factor receptor gene therapy affects cellular immune responses in collagen induced arthritis in mice. Ann Rheum Dis 64: 1550-1556, 2005.

17. Arnett FC, Edworthy SM, Bloch DA, McShane DJ, Fries JF, Cooper NS, Healey LA, Kaplan SR, Liang MH, Luthra HS, et al: The American Rheumatism Association 1987 revised criteria for the classification of rheumatoid arthritis. Arthritis Rheum 31: 315-324, 1988.
18. Xinqiang S, Fei L, Nan L, Yuan L, Fang Y, Hong X, Lixin T, Juan L, Xiao Z, Yuying S and Yongzhi X: Therapeutic efficacy of experimental rheumatoid arthritis with low-dose methotrexate by increasing partially $\mathrm{CD} 4{ }^{+} \mathrm{CD} 25^{+}$Treg cells and inducing Th1 to Th2 shift in both cells and cytokines. Biomed Pharmacother 34, 463-471, 2010.

19. Durie FH, Fava RA, Foy TM, Aruffo A, Ledbetter JA and Noelle RJ: Prevention of collagen-induced arthritis with an antibody to gp39, the ligand for CD40. Science 261: 1328-1330, 1993.

20. Tu Y: The discovery of artemisinin (qinghaosu) and gifts from Chinese medicine. Nat Med 17: 1217-1220, 2011.

21. Li T, Chen H, Wei N, Mei X, Zhang S, Liu DL, Gao Y, Bai SF, Liu XG and Zhou YX: Anti-inflammatory and immunomodulatory mechanisms of artemisinin on contact hypersensitivity. Int Immunopharmacol 12: 144-150, 2012.

22. O'Dell JR, Leff R, Paulsen G, Haire C, Mallek J, Eckhoff PJ, Fernandez A, Blakely K, Wees S, Stoner J, et al: Treatment of rheumatoid arthritis with methotrexate and hydroxychloroquine, methotrexate and sulfasalazine, or a combination of the three medications: Results of a two-year, randomized, double-blind, placebo-controlled trial. Arthritis Rheum 46: 1164-1170, 2002.

23. Aldieri E, Atragene D, Bergandi L, Riganti C, Costamagna C, Bosia A and Ghigo D: Artemisinin inhibits inducible nitric oxide synthase and nuclear factor NF- $\mathrm{NB}$ activation. FEBS Lett 552: 141-144, 2003. 